By

Miron Mushkat* and Roda Mushkat**

*Visiting Professor, Department of Politics and Public Administration, University of Hong Kong

**Professor and Director of the Center for International and Public Law, School of Law, Brunel University; Honorary Professor, Faculty of Law, University of Hong Kong 


\begin{abstract}
Hong Kong is a fascinating social laboratory where one can observe the interplay between powerful forces of modernization and deeply-entrenched pre-industrial consumption patterns. For decades, the former had not encroached on the autonomy of grassroots-style forms of health care, but the enactment of the Chinese Medicine Ordinance in 1999 has brought the latter under the grip of the state, albeit in the weak sense of the term. This particular episode may offer insights into the dynamics of the two-way adjustment that takes place when the divergent paths of the mainstream and traditional sectors inevitably cross, prompting regulatory and developmental responses.
\end{abstract}

Key words: regulation, traditional Chinese medicine, agenda setting, streams, windows, political economy, informal health care, demand side, supply side. 


\section{THE POLITICAL ECONOMY OF LOOSE REGULATION: MODERNITY MEETS TRADITION IN HONG KONG}

\section{Introduction}

"Rolling back the frontiers of the state" has crystallized into a virtual policy norm in industrial and industrializing countries alike in the past three decades or so. This trend has manifested itself on both the demand and supply sides of the economy. As the appeal of Keynesian ideas has diminished following the stagflationary pains experienced in the 1970's, their monetarist counterparts have regained their luster, providing an intellectual rationale for better fiscal discipline than during the long postGreat Recession era, which had generally been marked by a high degree of government activism. Public expenditures have been curtailed and taxes have been reduced in order to minimize the "crowding out" of private consumption/ investment and dampen inflationary pressures. Monetary policy instruments, rather than ones of the fiscal variety, have increasingly been relied upon as the principal tool in the pursuit of economic stabilization (Bailey 1995; Bailey 1999; Bailey 2004).

Supply-side measures designed to eliminate impediments to output expansion have been embraced in a determined fashion. Some of the steps taken have been directed at private markets and have featured far-reaching reforms of the institutional channels for the mobilization of key factors of production (capital, labor, and land) and the delivery of goods and services. Others, perhaps even more radical in nature, have focused on supply-side rigidities in the public sector and have encompassed initiatives ranging from the macro to the micro end of the policy spectrum. Fiscal restraint falls into the former category (rather than merely being a reflection of conservative demand management) because lower public expenditures/taxes are apparently conducive to robust output growth (e.g., by stimulating productive endeavor in the private sector and improving incentives to work) and so does the revamping of specific public programs (e.g., the social security system, perceived to be the source of a pervasive dependency culture; Bailey 1995; Bailey 1999; Bailey 2004). 
The efforts at micro-style re-engineering have included a host of innovative, although not uncontroversial, policy responses. The overarching goal has been to curb the incidence of non-market failure/ enhance government efficiency and transfer activities from the public to the private sector wherever realistically possible. For this purpose, new (or revitalized) institutional structures have been introduced on a large scale, the most prominent being: external markets (created through competitive tendering for service inputs and non-competitive/ competitive contracting for service outputs), internal markets (e.g., for hospital services), semi-autonomous public agencies, user charges, purchaser-provider split (where service funding and service production may originate in different sectors), public-private joint ventures in various forms (e.g., private financing of public projects via the Private Finance Initiative/ PFI), administrative devolution, wholesale privatization of public enterprises, and deregulation (Bailey 1995; Bailey 1999; Bailey 2004).

These seismic policy shifts have had surprisingly modest reverberations in Hong Kong. The fiscal balance has recently returned into positive territory, but the government had been saddled with stubborn deficits for several years following the Asian financial crisis of 1997/98. Technically speaking, the budget had been a source of expansionary impulses during that period, albeit hardly powerful in nature, and the fiscal authorities had not been averse to occasionally and opportunistically promoting capital intensive projects as a means of shoring up the cyclically challenged economy. There is limited scope for maneuver in Hong Kong in the monetary domain, due to constraints imposed by the linked exchange rate system. Nevertheless, the regulators have been stretching their tentacles even in this seemingly neutral sphere. Dramatic currency intervention in support of the Hong Kong dollar, when the target of intense speculative market pressures, is the most telling case in point, but in some respects it may be viewed as merely the tip of a policy iceberg (Jao 2001; Wan et al. 2007).

Moreover, the supply side of the economy has received scant strategic attention. The deregulation of the telecommunications industry has been implemented in a decisive manner. The underground rail network (Mass Transit Railway Corporation, MTRC) has been partially privatized with considerable fanfare and the fully corporatized overground rail network (Kowloon-Canton Railway Corporation, KCRC) is being smoothly absorbed into it. There has also been selective privatization and 
commercialization of public housing in the territory. Two other developments worth highlighting are the establishment of the Housing Authority (HA), an "independent" organization responsible for managing all public hospitals in Hong Kong (it remains accountable to the government through the Secretary for Health and Welfare), and the Electrical and Mechanical Services Trading Fund, an entity which operates as an integral part of the bureaucratic machinery but on a commercial basis (it qualifies as a variant of "contracting in," as distinct from "contracting out"; Rabushka 1973; Rabushka 1976; Rabushka 1980; Woronoff 1980; Cheng 1982; Youngston 1982; de Mesquita et al. 1985; Peebles 1988; Ho and Chau 1989; Mushkat 1990; de Mesquita et al. 1996; Lethbridge and Ng 2000; Jao 2001; Ash et al. 2003; Mushkat and Mushkat 2006a; Wan et al. 2007).

The International Airport, Post Office (known as Hong Kong Post), and the Water Supplies Department are high-profile candidates for privatization at some future juncture. In fact, the airport already functions along the lines of the public hospital system by virtue of being overseen by a body (the Airport Authority, AA) structured in a similar fashion to the HA. However, the timing of changes in the status of these three organizational vehicles remains distinctly uncertain. As matters stand, the process of liberalization (an all-embracing term) within and without the public sector is not evolving in a very dynamic manner. There has been a clamor in unofficial policy circles for broadening the focus and accelerating the pace, yet the government is apparently not in a hurry to elevate this into a high priority item and recalibrate relevant strategies (Kwong 1988; Kwong 1990; Mueller 1991; Hall 1996; Cheng and Wong 1997; Ho 1997; Lam 1997; Lam and Chan 1997; Cheng and Wu 1998; Wong 1998; Wong 1999; Lam and Chan 2000; Jao 2001; Burns 2004; Scott 2005; Mushkat 2006; Wan et al. 2007).

Bureaucratic lack of urgency in this respect is not entirely inconsistent with institutional realities. By international standards, Hong Kong has a comparatively small public sector which has traditionally been content to follow, while displaying considerable caution in the process, its private counterpart. The policy framework has been fined-tuned over the years, to reflect fundamental shifts in the external and internal environment, but the core principles have not been overhauled. The strategy of positive non-interventionism, articulated by visionary financial secretaries more 
than a quarter of a century ago (initially by John Cowperthwaite in 1971 and more emphatically by Philip Haddon-Cave in 1980), has not been diluted significantly and continues to serve as a roadmap for the current generation of policy makers. Given this backdrop, Hong Kong may be less concerned about public-private economic imbalances than other countries/ territories and less tempted to tinker with the established institutional architecture (Rabushka 1973; Rabushka 1976; Rabushka 1980; Woronoff 1980; Cheng 1982; Youngston 1982; de Mesquita et al. 1985; Peebles 1988; Ho and Chau 1989; Mushkat 1990; de Mesquita et al. 1996; Lethbridge and Ng 2000; Jao 2001; Ash et al. 2003; Mushkat and Mushkat 2006a; Wan et al. 2007).

The reluctance to embrace liberalization unambiguously may also be the product of post-1997 uncertainties. The transition from British to Chinese rule has proceeded smoothly, on the face of it, but the transfer of sovereignty from a colonial power governed by the rule of law to a country where the rule of man shapes political outcomes has injected an element of unpredictability into the decision making calculus of economic agents. Perhaps more importantly, Hong Kong suffered a series of exogenous shocks, reinforced by disorderly endogenous adjustments, which had a deleterious effect on domestic confidence. The 1997/98 Asian financial crisis drove the economy into a slump and contributed to a plunge in property prices. Serious environmental hazards, notably bird flu and severe acute respiratory syndrome (SARS), aggravated the problem. As a result, economic activity ground to halt, unemployment surged, wages stagnated, corporate profits sank, and asset prices plummeted. Beleaguered consumers and investors retreated into their shells in the face of these pressures and the government resorted, willingly or otherwise, to counter-cyclical remedies (again, primarily fiscal in nature, because of the monetary constraints imposed by the linked exchange rate system) in order to stabilize the economy. The relationship between private initiative and bureaucratic response has inevitably undergone at least a mild transformation in the process (Jao 2001; Lethbridge and Ng 2000; Ash et al. 2003; Mushkat and Mushkat 2006a; Mushkat and Mushkat 2006b; Wan et al. 2007).

Institutional realignments induced by exogenous shocks, particularly if highly disruptive and/ or cumulative in nature, while not irreversible, tend to become 
embedded in the politico-economic fabric. As argued and demonstrated by Peacock and Wiseman, a crisis or equivalent prompts a policy reaction specifically tailored to the prevailing circumstances, but when the immediate pressures abate, the forces of inertia prevent a quick reversion to the status quo ante. A semi-permanent "displacement" thus materializes and a new institutional configuration emerges. This pattern was observed following the Great Depression and the Second World War. Both events called for a wide-ranging and forceful government response to the enormous challenges of the day, but they also reshaped the public-private balance in a way that had affected the modus operandi of the economy for years to come (Peacock and Wiseman 1961). It might not be appropriate to overstate the relevance of this experience for post-1997 Hong Kong, yet the analogy may have some validity.

Another factor that may need to be considered in this context is the impact of socioeconomic change on government strategic positioning. The Hong Kong economy has displayed great dynamism since the Second World War. Quantitatively, the pace of output expansion has been very rapid and, qualitatively, the economic structure has undergone several far-reaching transformations. The standard of living has risen substantially and, as "Wagner's Law" (which posits that public expenditure is highly elastic with respect to national income) would have predicted (Bird 1971), the demand for government services has grown stronger. Gradual democratization has opened channels for consumers to express their "voice" and policy makers, again whether as part of a deliberate design or by default, have reacted by adopting a moderately active posture by historical standards (Leung 1996; Lo 1997; Lo 2001; Leung 2003; Ma 2007).

Such influences of both external and internal origin may account for various post1997 government initiatives, which perhaps would have not seen the light of day in different circumstances, would have been implemented later rather than sooner, would have been pursued less vigorously, or would have been scaled down. The enactment of the Chinese Medicine Ordinance on July 14, 1999, is one case in point. While this piece of legislation had been long in the making, it nevertheless constituted a clear departure from prevailing policy practices and in principle symbolized a shift, a possibly belated one from a historical perspective, from an essentially traditional to a fundamentally modern regulatory regime. As such, it is worth dissecting not merely 
as an intriguing example of government intervention in an institutional environment characterized by built-in restraints but also for its broader ramifications. This is the purpose of the present paper.

Analyzing an ordinance/ policy is inevitably a multi-dimensional process because of the complexities involved. One may focus on content, process, outcome, or some combination of the three. By the same token, the research emphasis may be placed on description, explanation, evaluation, or (again) a blend of sorts of the three approaches (Table 1). The specific strategy adopted may reflect contextual considerations, disciplinary predispositions (mostly legal versus social science frames of reference), empirical opportunities/ constraints, and the overall objective of the exercise. Here our ultimate goal is to explain systematically, in theoretical terms wherever feasible, what forces propelled Hong Kong regulators in this particular instance and what general lessons can be drawn regarding their modus operandi in light of that experience. The paper thus exhibits a process orientation, but it progresses toward its core in a stepwise fashion.

(Insert Table 1 about here)

\section{From Process to Content, Descriptive Facets}

Although it had attracted scant official attention throughout most of Hong Kong's colonial history, traditional Chinese medicine (TCM) had at no juncture been relegated to the periphery of the territory's health care system. It had managed to survive, or even thrive, despite the lack of overt bureaucratic interest (indeed, it is tempting to argue that this benign neglect had contributed to its resilience over the years). Surveys conducted by the government and academic research centers attest to the wide acceptance of TCM and, more importantly, extensive reliance upon it by the local population. Recent findings suggest that 23 percent of all primary care consultations are provided by TCM practitioners and that 27.9 percent of people are either content to depend exclusively on traditional forms of medicine or prefer to combine them with their modern counterparts (Gambert 1994; Wong 1999; Gauld and Gould 2002). 
The paucity of surveys, both official and unofficial, focusing on this phenomenon precludes observations extending beyond such general statements. It is thus not possible to trace the evolution of TCM in precise terms or offer any meaningful insights about specific patterns of utilization (outcome effectiveness is an even more elusive subject). However, there is reason to believe that TCM has experienced considerable growth and service expansion over time notwithstanding Hong Kong's rapid modernization. This is doubtless largely attributable to the ethnic composition of the local population (95 percent Chinese) and the nature of colonial rule (the noninfringement by the British administration, in Hong Kong and other similar settings, on indigenous cultures and traditional lifestyles; Gambert 1994; Wong 1999; Gauld and Gould 2002).

Public policy had been conducive to the development and entrenchment of TCM by virtue of the climate of tolerance underpinning it and the non-interventionist ethos shaping bureaucratic responses in specific contexts. Unlike the practitioners of modern medicine, who are governed by the Medical Registration Ordinance and accountable to the Hong Kong Medical Council, those operating in the traditional sector had historically been constrained merely by the Companies Ordinance. Until the promulgation of the new legislation in 1999, any person who so desired could proceed to register as a business and offer TCM services in an unfettered fashion. In the absence of effective regulation by a professional association, there had been significant variation among dispensaries and practitioners in education, training principles supporting patient care, procedural guidelines, product standards, and commercial requirements (Wong 1999; Gauld and Gould 2002).

TCM service providers in Hong Kong fall into three broad categories: (1) herbalists the physically most prominent segment of the trade - who primarily prescribe and dispense herbal composites for internal medical care via a territory-wide network of retail outlets (normally featuring cabinets of herbs with their distinctive aromas); (2) acupuncturists, who enjoy considerable recognition and following beyond the Chinese/Asian communities; and (3) bonesetters - the least visible element of the profession - whose narrower specialty involves the treatment of bruises, fractures, and sprains. The number of practitioners in these areas exceeds 8,000 , which is approximately the same magnitude as the more reliable figure available for the 
modern side of medical care. TCM service providers belong to at least a dozen of different "professional" associations, which are believed to attract roughly half of those active in the field (Wong 1999; Gauld and Gould 2002).

Historically, the route to TCM practitioner status was through an apprenticeship or self-education, with the former being more common than the latter. Formal training, coupled with proper registration, was the exception to the rule. The picture has changed in recent years and multi-year institutional learning, which culminates in the acquisition of generally recognizable qualifications, has become the norm. Despite the trend toward standard enhancement, the trade as a whole continues to be influenced by patterns prevailing in the past. Reliance on self-prescription, as distinct from TCM service provider guidance, also remains widespread. This, as well as uncertain product quality control procedures (by no means an exclusive Hong Kong phenomenon) and a weak form of consumer protection, has resulted in a proliferation of cases of illness and death arising from the distribution of hazardous and poisonous substances. An awareness of TCM side effects has thus increased and practitioners have lost their virtual invincibility by turning into targets for malpractice claims (Wong 1999; Gauld and Gould 2002).

Occasional bouts of negative publicity have done little to dim the appeal of TCM at the grassroots level. Consumers seem to draw a distinction between the source and the channel of delivery. They apparently consider the products/treatments, in the appropriate form, as basically safe and potentially beneficial. On the other hand, they often tend to display low confidence in TCM service providers. As no surveys of official attitudes have been conducted, there is greater ambiguity regarding the specific nature of bureaucratic concerns. Actions taken, documents published, and views expressed over the past three decades or so suggest that sentiments exhibited by consumers and regulators/ would-be regulators have not diverged materially in this respect, although differences may be noted in problem definition and mode of communication (Lee 1980; Wong, Wong, and Donnan 1993).

It would be inaccurate to imply that government stance vis-à-vis TCM had undergone a transformation as British colonial rule had entered its final phase. By the same token, it would be unproductive to search for possible trigger points for greater policy 
activism. The shift had not been a reflection of a fundamental philosophical readjustment. Similarly, the process of bringing TCM into the regulatory domain had been gradual rather than abrupt. That said, a number of events/initiatives may be identified as having catalyst-like effects and meaningful long-term strategic consequences. The first was the establishment in summer 1989 of a Working Party on Chinese Medicine (WPCM) to address systematically problems confronting the traditional health care sector.

The WPCM had a dual purpose: to generate enlightenment and to offer direction. To this end, independent experts, predominantly with an academic background, were invited to join it, in addition to representatives from the official side. Their role was by no means confined to the production of relevant information, which was sorely missing, but they did play a crucial part in devising and implementing data-collection exercises. This proved to be a labor-intensive undertaking, extending over several months and involving the examination of policy frameworks and professional practices elsewhere (chiefly China and Taiwan). The WPCM delivered its first official verdict, in the form of an interim report, in late 1991 (such bodies often communicate their findings in two steps, allowing for feedback before proceeding to the final destination).

The report contained a number of concrete proposals regarding the functioning of the traditional health sector which constituted a clear departure from historical patterns. Notably, it recommended that practitioners be required to register with an authoritative industry-wide association which would assume responsibility for the setting and monitoring of standards. The report also suggested that effective controls be imposed on a number of potentially harmful herbs that were restricted in other jurisdictions (again, primarily China and Taiwan), yet readily available in Hong Kong. While stopping short of advocating a strict system of registration, which would prevent those not able to cross this barrier from writing prescriptions, the report put forward the idea of a provisional list of around 70 identified potent and toxic herbs that should be made available together with formal warnings on the risks inherent in using TCM without proper advice. Perhaps unsurprisingly, given the historical backdrop and conservative institutional setting, a piecemeal adoption of the 
proposals, in order to minimize disruption to suppliers and consumers, was deemed appropriate in the circumstances (Working Party on Chinese Medicine 1991).

The response to the report was generally favorable, but not unambiguously so, and some stakeholders emphasized the need for fine-tuning. Interestingly, the reforms outlined provoked no backlash from the traditional health care sector. On the contrary, those who acted as its spokespersons expressed support for the key recommendations. The potentially controversial suggestion to introduce a registration mechanism, amounting to professional regulation (or, to state it more precisely, selfregulation), was embraced on the grounds that it would enhance standards (and, by implication, the status of the trade) and be conducive to consumer well-being. The idea of distributing in a transparent fashion a list of toxic herbs was also endorsed for broadly similar reasons (it should be noted that such measures were rightly seen as rendering practitioners less vulnerable to malpractice claims; Wong 1999; Gauld and Gould 2002).

The mild criticisms that surfaced were directed at the lack of "positive" steps to place TCM on a firmer footing (as distinct from largely "negative" ones designed to circumscribe it). In particular, it was argued that the loosely organized and resourcepoor sector could benefit from meaningful government involvement in professional training. The pleas to this effect were viewed constructively by the Panel on Health Services of the Office of the Members of the Executive and Legislative Councils (OMELCO), an executive-legislative organ performing policy screening functions. In that vein, it proceeded to make the following proposals: (1) that TCM should be incorporated into Hong Kong's tertiary curriculum under the auspices of an Academy of Chinese Medicine; (2) that TCM practitioners should be registered, with clear distinctions drawn between herbalists and Chinese medical practitioners and the possible granting of professional status to the latter; (3) that TCM practitioners should not be barred form using thermometers and other similar instruments; and (4) that channels should be established to enable the TCM sector to provide input into government decisions impinging on its structure and performance (Wong 1999; Gauld and Gould 2002). 
The Legislative Council (LEGCO) served as the arena for publicly assessing the merits and demerits of the various recommendations, with the visible and invisible hands of the executive arm (i.e., relevant segments of the bureaucracy) defining the rules of the game and offering strategic guidance. Following a completion of a number of rounds of executive-legislative exchanges, the WPCM resumed its work on the final version of the report. The processing and consolidation of the ideas put forward was expected to be a relatively straightforward affair, but the effort somehow defied predictions of a speedy conclusion. After a series of false starts, the report was eventually issued in 1994, bolstered by government contentions that the delays were the result of the complexity of the subject under scrutiny, many submissions received, and elaborate consultations required. TCM representatives were more inclined to attribute the difficulties experienced to a lack of urgency on the official side and bureaucratic inertia. They also signaled their dissatisfaction with the degree of involvement on their part at this crucial stage (Wong 1999; Gauld and Gould 2002).

As might have been expected, the final WCPM report retained the core of its predecessor and liberally incorporated most of the feedback generated following the latter's release. The report was not couched in unambiguously normative terms. The WPCM opted to delegate the task of producing a detailed blueprint and translating its vision into a concrete plan of action to a preparatory committee. Such an organizational vehicle was thought to be better suited for taking the mission of laying the foundations for a sound and workable statutory framework for the orderly development, promotion, and regulation of TCM. Accordingly, the report aimed at striking a balance between fully utilizing the substantial information, both descriptive and normative, that had been accumulated over a five-year period and not restricting unduly the room for maneuver of the new body.

In the end, the WPCM bequeathed the following (non-binding) suggestions to its successor: (1) that the preparatory committee should compile a list of active TCM practitioners for potential registration and determine criteria and procedures to be employed for this purpose; (2) that it should publish a list of toxic herbs; (3) that the statutory entity to be established should limit availability of potent herbs to only patients with prescriptions from registered TCM practitioners; (4) that health and sanitary standards of TCM manufacturers should be exposed to regulatory oversight; 
(5) that importers of herbal medicines should be licensed along with their products and registered with the statutory entity; (6) that a proper training infrastructure should be built in order to propel TCM in a more professional direction; (7) that local tertiary institutions should be encouraged to broaden and deepen their TCM research and teaching programs; (8) that adequate training should be offered to dispensers of herbs (a "marginal" component of the trade); (9) that they should be registered with the statutory entity; and (10) that the Department of Health should intensify its efforts to raise in a multi-faceted fashion public awareness of TCM (Working Party on Chinese Medicine 1994).

The notion of creating an effective organizational vehicle to set the stage for legislative conversion of the ideas generated during the initial phases of the policy adjustment process was promptly embraced by the bureaucracy. Indeed, when unveiling the final WPCM report, the Secretary for Health and Welfare announced that a Preparatory Committee on Chinese Medicine (PCCM) would be established to pave the way for the formation of the statutory entity, to fulfill the ultimate goal of insuring the emergence of a properly self-governing and regulating TCM profession. However, no timetable was provided for proceeding toward this objective and for the passage of the ensuing legislation. By the same token, no concrete measures were implemented to shift any of the WPCM proposals (notably, those regarding registration and handling of toxic herbs) from the theoretical to the practical domain. Instead, a preference for progressing in a stepwise manner and not tinkering with the institutional status quo before 1997 was indicated (Wong 1999; Gauld and Gould 2002).

The ambiguous signals emanating from high-level official sources notwithstanding, the PCCM came into existence in early 1995. Its composition reflected a desire to secure a high degree of legitimacy in that it consisted of a mixture of civil servants, academic experts, TCM practitioners, and informed/interested community leaders. The committee was given two years to pursue its mission. The 21-member PCCM quickly formed a series of working groups to examine specific WPCM recommendations, via further fact-finding (including through additional consultations with trade representatives) and analytical inquiries. This proved to be a challenging exercise because of difficulties encountered in obtaining data relating to service 
providers (number, qualifications, and practices) and compiling a list of toxic herbs (from a vast universe with often little known ingredients). To complicate matters, the task was managed in the face of escalating media attention to the dark side of TCM (Wong 1999; Gauld and Gould 2002).

Despite such headwinds, the PCCM delivered its findings in early 1997, as planned, and had its term immediately extended for another two-year period in order to solidify its proposals. The mainstay of the PCCM report was a recommendation to establish a statutory Council on Chinese Medicine. Consistent with the tone of similar past documents, this was envisioned as a gradual undertaking minimizing disruption for the traditional health care sector. The basic proviso was that all practitioners would have to satisfy the registration criteria - passing a universal licensing examination as a condition for joining the profession. At the same time, it was deemed appropriate, given the historical backdrop, to grant exemptions from this requirement to service providers with experience of ten years or more, or those combining substantial exposure to the trade with a recognized TCM qualification. The PCCM suggested an assessment test for practitioners not meeting these benchmarks, with a mandatory examination for those with less than five years' exposure (Preparatory Committee on Chinese Medicine 1997a; Preparatory Committee on Chinese Medicine 1997b).

For the large number of service providers not falling into any of these categories, the report proposed that they be permitted to carry out their activities without interruption subject to the stipulation that they undertake formal training leading to professional validation through passing of the licensing test. The PCCM reaffirmed in general terms the importance of regulating medicinal substances in the interest of consumer safety. On the positive side, the need was highlighted for concrete steps to obtain a wider recognition of TCM within the health care system of Hong Kong and society as a whole, for effective measures to encourage rigorous scientific research in this area, and for comprehensive strategies to incorporate TCM into tertiary education curricula. In accordance with prevailing institutional norms, the government formally sought feedback to the PCCM proposals (Preparatory Committee on Chinese Medicine 1997a; Preparatory Committee on Chinese Medicine 1997b). 
After such lengthy deliberations, involving key stakeholders in an open, albeit not uniformly equitable fashion, the proposals generally reflected the emerging consensus within and without the policy establishment and pressures mounted for legislative enactment. This materialized on July 14, 1999, with the adoption of the Chinese Medicine Ordinance by LEGCO. The statutory framework created was firmly grounded in the principle of self-regulation. The Chinese Medicine Council, an 18person strong body set up in September 1999 - comprising representatives of the TCM sector, academic/ independent experts, civil servants, and lay persons - was charged with the responsibility for devising and implementing appropriate regulatory measures, including those pertaining to the use, manufacture, and distribution of medicinal substances (Chinese Medicine Council of Hong Kong 2006).

The Chinese Medicine Council operates via two Boards, one focusing on practitionerrelated issues and one handling matters concerning medicinal substances. Registration of service providers looms large on the agenda of the former. In this respect, following the full implementation of the Chinese Medicine Ordinance, it was envisioned that all practitioners would have to be registered as a condition for practising TCM in Hong Kong. Two requirements would have to be met prior to crossing this professional hurdle. First, the applicant would have to pass a licensing examination. Second, to be able to take the test, he/she would have to satisfy the Chinese Medicine Practitioners Board that he/she successfully completed undergraduate training in TCM or its equivalent as approved by the Board (Chinese Medicine Council of Hong Kong 2006).

Transitional arrangements were made to minimize disruption on the demand and supply sides. Thus, applicants who had been providing traditional health care in Hong Kong continuously for not less than fifteen years up to January 3, 2000, were exempted from the licensing examination/ registration assessment and were allowed to formalize their status unconditionally. Applicants who had less than fifteen but more than ten years of such experience, and academic qualifications acceptable to the Chinese Medicine Practitioners Board, were granted the same exemption. Applicants with equivalent experience, but lacking the necessary academic qualifications, were subjected just to the registration assessment, having to sit the licensing examination only in the event of a failure at that stage. Similar rules were employed for applicants 
with less than ten years' experience with acceptable academic qualifications, whereas those without such qualifications were expected to pass the licensing examination (Government of the Hong Kong Special Administrative Region 2000).

Mandatory registration is not the sole regulatory mechanism relied upon by the Chinese Medicine Practitioners Board, even though it overshadows the others. The Board also issues and endeavors to enforce guidelines regarding continuing education in TCM in order to prevent erosion of professional standards and insure crossfertilization with the avant-garde research community. By the same token, it designs, and redesigns if necessary, a code of practice for service providers. This regulatory device encompasses norms pertaining to the discipline, ethics, and responsibility exhibited by TCM practitioners in the course of their work. Deviation from the norms may prompt a formal inquiry, possibly culminating in punitive action, including a removal from the Register of Chinese Medicine Practitioners (Leung and Chan 2004; Chinese Medicine Council of Hong Kong 2006).

Registration of medicinal substances, as distinct from that of service providers, falls within the purview of the Chinese Medicines Board. In this context, medicinal substances, or proprietary Chinese medicines (PCM) in technical parlance, refer to any products composed exclusively of Chinese herbal medicines or materials of animal, herbal, or mineral origin traditionally used in whatsoever material or medicinal form. According to the Chinese Medicine Ordinance, any PCM manufactured in Hong Kong should be registered by the producer. For substances originating elsewhere, the process should be undertaken either by the importer or the local representative of the manufacturer. Some minor exemptions are available and, again, transitional arrangements were made to secure a reasonably smooth shift to the new regulatory regime (Leung and Chan 2004; Chinese Medicine Council of Hong Kong 2006).

PCM are classified into three categories: well-established drugs, not well-established drugs, and new drugs. Each of these is subject to somewhat different registration requirements. It should be noted that the Chinese Medicines Board approval is contingent on receipt of test reports, in addition to standard documents. The former are mostly offered by local and mainland-based laboratories. They address 
pharmacodynamic, pharmacological, and safety issues in a manner consistent with technical provisions set by the International Standards Organization (ISO). The mainland-based entities are recognized by the State Food \& Drug Administration (SFDA). The Chinese Medicines Board effectively imposes an extra layer of controls (Leung and Chan 2004; Chinese Medicine Council of Hong Kong 2006).

The Chinese Medicine Ordinance has attracted some criticism for its relative lack of attention to potentially positive measures to enhance the functioning of TCM and facilitate its integration into the broader health care system. It is a moot point whether this is a problem which can be targeted effectively through legislative initiatives, however constructive. Subsequent policies have been geared toward achieving these twin objectives, although there are legitimate questions regarding scope and intensity. TCM is enjoying a renaissance in the academic domain, both on the pedagogical and research fronts. A number of specialized out-patient clinics have started operations, but the idea of a hospital dedicated to the subject has not come to fruition. Progress is thus recorded, yet the overall picture remains mixed, and it is premature to suggest that TCM has evolved into an integral part of a multi-dimensional and finely balanced health care system (Wong 1999; Mok 2001; Gauld and Gould 2002; Leung and Bacon-Shone 2006; Wong et al. 2006).

\section{Process Revisited, Explanatory Facets}

Hong Kong has followed an economic path that qualifies as unique in several aspects. In absolute terms, policy restraint may have fallen short of orthodox economic tenets, but from a comparative perspective it has been virtually without parallel. In recent years, more government intervention has been observed than in the past, at times not entirely productive in nature. However, this has not been a linear trend. The deregulation of the telecommunications industry, which assumed the form of "shock therapy," and the dismantling of the interest rate cartel/ financial liberalization, which was conducted in a more delicate fashion, are two examples of a deliberate effort to promote vigorous competition. Steps have also been taken in the opposite direction, whether decisively or tentatively. For instance, pollution controls have been extended in a stepwise manner and, as illustrated here, TCM is no longer a law unto itself. 
Such changes in the regulatory framework, whether abrupt or gradual, may legitimately be portrayed as seismic because of the inherently static propensities of Hong Kong's supposedly "rule-driven" (as distinct from one shaped by "policy discretion") government decision-making apparatus. In this type of a politicoeconomic environment, particularly if the rules display considerable resilience, it is common to encounter a high degree of institutional inertia. For that reason, one would expect significant departures from the regulatory status quo to be of strong interest to legal scholars and social scientists. Yet, this has not been overwhelmingly the case. Some policy areas have loomed larger on the research agenda than others but, on the whole, the analytical output cannot be described as substantial. Moreover, heavy emphasis has been placed on evaluation, with the explanatory side generally being relegated to the periphery.

The health field has fared better than most. Nevertheless, even here a pronounced normative bias has consistently manifested itself in the studies undertaken. Evaluation underpinned by microeconomic logic, doubtless valuable in itself, has proved specially appealing to both those conducting the investigations and their sponsors (a typical example is Hay 1997). To complicate matters, the attention accorded to TCM has been distinctly modest, perhaps understandably so. Currently, there are merely two major published works offering explanatory insights into government strategies vis-à-vis the traditional health sector. One is devoted exclusively to TCM and the other is focused on the system in its entirety within a theoretical structure that can comfortably accommodate the traditional component. Both studies, which are presented faithfully albeit selectively below, make an important contribution to knowledge, but they leave some questions unanswered, notably from a regulatory standpoint.

The first of these two published works was written by Polly Ho, a researcher affiliated with Hong Kong Polytechnic University. She aimed at determining empirically what furnished the trigger for the apparent turnabout in government attitude toward the regulation of TCM, following a long period during which the bureaucracy was to all intents and purposes perfectly content to turn a blind eye to traditional health care in its various forms. The specific issues her paper addresses in considerable detail are: Why did the policy reversal materialize at that particular juncture? Which parties were 
involved in the process? How did the subject become incorporated into the government agenda and, subsequently, into its decision counterpart (Ho 2002)?

An attempt to draw a distinction between different types of public agendas was made originally, in the American context, by Cobb and Elder. They chose to highlight the evolution of policy problems from their initial stages when little official recognition is accorded to them to a point whereby such recognition is fully granted. This led to a distinction between systemic and institutional agendas. The former consist of issues deemed worthy of public attention by members of the political community and the latter of ones actively considered by the government (Cobb and Elder 1983). Kingdom took that a step further by differentiating between two late-stage policy configurations, governmental agendas to which serious official attention is being paid, and decision agendas whose emergence closely precedes authoritative action (Kingdom 1997).

Ho opted to conduct her analysis within the Kingdom framework, which was put forward as a conceptual vehicle for tracing the progression of policy initiatives from early to final stages of agenda setting. The progression, according to Kingdom, can be explained in terms of the operations of three factors/streams centering on problems, policies, and politics. The problem stream addresses the perceptions of social issue and the circumstances under which it comes to be seen as an undesirable state of affairs meriting a corrective response. The policy stream focuses on informed participants formally engaged in issue dissection, examination of remedial measures, and assessment of the pros and cons of alternative courses of action. The political stream refers to forces, tangible and intangible (e.g., interest group maneuvers versus swings in the public mood), in the political arena that impinge on problem management (Kingdom 1997).

Kingdom posits that these three streams flow/operate more or less independently of each other until they coalesce at certain points in time. At such junctures, windows normally open, propelling a given social issue firmly onto the agenda setting stage. The convergence of the three streams is a necessary, but not sufficient, condition for this outcome to materialize. A window may open fortuitously or due to opportunities typically arising from institutionalized events (e.g., budget formulation or an 
election), yet in most circumstances a further catalyst is needed. That is generally furnished by political entrepreneurs, within and/or without government, who persist in drawing attention to problems, indefatigably searching for solutions, and resourcefully seeking ways to generate political support (Kingdom 1997).

Ho identified negative publicity as the principal factor prompting concerns regarding dubious practices by TCM service providers and harmful side effects associated with traditional medicinal substances. Such concerns surfaced in the 1970's and had intensified in subsequent years. Over time, they had helped to bring about a conversion of a seemingly peripheral social issue into one commanding considerable public attention, albeit not necessarily at the grassroots level. A problem stream had thus emerged. It is interesting to note in this respect that, in the period leading to the establishment of the WPCM in 1989, several cases of malpractice and poisoning were reported. In some instances, serious remedial measures had to be resorted to in modern medical (including hospital) settings and at least one person died apparently after consuming Chinese herbs (Ho 2002).

The case of two restaurant workers who fell into a coma in February 1989 turned into a cause celebre and unleashed powerful pressures that proved difficult to contain. The brother of one of the victims happened to be an experienced biochemist/pharmacologist and he was able to determine scientifically that the two were given a cheaper but toxic version of a herb generally thought to be safe (To Yee Chat rather than Lung Dam Cho). He petitioned LEGCO, where his expressions of profound dismay found sympathetic ears. A small but vocal group of legislators, elected as well as appointed, was alarmed by the "Lung Dam Cho incident" and proceeded to launch a fierce attack on the government for its cavalier attitude toward traditional health care. The WPCM was consequently born (Ho 2002).

The formation of the WPCM was the first step in the unfolding of the policy stream. The series of strategic institutional initiatives that followed was outlined previously and featured the establishment of the PCCM, the promulgation of the Chinese Medicine Ordinance, and the creation of the Chinese Medicine Council. A number of concrete policy proposals crystallized in this context, some of which were embraced while others were not (although there were few categorical rejections). The need for a 
statutory regulatory entity, a notion first floated in the 1970's, was reaffirmed. The desirability of exercising control through regulation of both TCM practitioners and medicinal substances was acknowledged. Ideas such as setting up a full-fledged TCM hospital (including an affiliated training facility) and integrating traditional medicine unambiguously into the modern health care system were explored tentatively but not conclusively (Ho 2002).

The courses of action placed on the strategic agenda and dissected were the product of analytical and promotional efforts of policy entrepeneurs of different backgrounds. Ho concluded that TCM practitioners played a prominent role in the process, particularly in the years following the formation of the WPCM. They were fortunate to have a high-profile de facto spokesperson, who served as a member of the Basic Law Consultative Committee (BLCC) and turned out to be a versatile representative of the profession. The voice of modern medicine was primarily channeled via LEGCO, where two Western-trained doctors consistently expressed their dissatisfaction with the state of traditional health care and the complete absence of regulatory constraints. A number of senior civil servants too were intimately involved in policy formulation although, rightly or wrongly, Ho suggests that the government was content to stay largely in the background. Academic experts were given the opportunity to influence strategic deliberations by being coopted, along with the principal stakeholders, into the WPCM and the PCCM (Ho 2002).

On the political (stream) front, Ho accorded considerable importance to the partial democratization that Hong Kong experienced in the mid-1980's. As the territory started positioning itself for the transition from British to Chinese rule, the Basic Law Drafting Committee (BLDC) and its consultative counterpart (BLCC) were established. Perhaps more significantly, in the present context, the composition of LEGCO underwent marked changes. As many as 43 percent of its members entered the legislative arena through the electoral route, albeit indirectly. Not being dependent on direct government sponsorship, exercised historically via the appointment mechanism, they were more willing to flex their muscles than their predecessors. This, as well as the climate of political uncertainty induced by the approaching transfer of sovereignty, helped to foster a relatively liberal atmosphere in 
which legislators (and interest groups) felt less restrained in challenging prevailing official wisdom (Ho 2002).

The Chinese authorities mostly opted to stay out of the TCM picture as the process of drafting the post-1997 constitution began to gain momentum. On the face of it, they seemed to be more favorably disposed toward Western-trained doctors, who were granted direct and indirect access to the BLDC and BLCC. However, they by no means discouraged belated attempts by traditional health care providers to organize with a view to insuring a modicum of participation on their part in the BLCC. Further, when one TCM practitioner secured a membership in that body, they apparently offered him tacit support. From a quantitative perspective, as distinct from a symbolic one, their essentially positive but not formally articulated posture, duly reflected in BLDC sentiment, was of greater importance. The Basic Law drafters were predominantly from the mainland and, individually and collectively, presumably with a quiet encouragement from the power center in Beijing, they conveyed the impression that TCM should be placed on a firmer footing. By contrast, the Hong Kong officialdom generally endeavored to maintain an aura of neutrality, partly in order not to constrain the post-1997 regime (Ho 2002).

It may legitimately be argued that these forces combined to transform TCM from an unattended social issue into one capable of capturing the attention of the bureaucratic establishment and compelling it to respond in concrete terms to the challenges it posed. Traditional health care thus emerged from public obscurity to attain the status of a worthy item on, first, the government agenda and, then, its decision counterpart. The influences exerted by the problem, policy, and political streams probably account for this outcome in one form or another. The 1989 intoxication case may have well proved to be a critical factor in that dynamic equation by triggering a chain of events which led to the inevitable conclusion. Despite the unfortunate circumstances, to paraphrase Kingdom, it may have been instrumental in opening a window that perhaps might have otherwise remained closed somewhat longer (Ho 2002).

The second work that sought to explain the evolution of TCM in Hong Kong and government strategies vis-à-vis the sector was written by Victor Wong, a leading student of the socio-economic dimensions of the territory's health care system. His 
study took the form of a comprehensive and intellectually ambitious survey of the structure in its entirety and was published as a book rather than as a journal article. One chapter in the book is devoted to informal health care, a term that encompasses TCM. Wong chose to examine his subject, in general and in relation to the informal/ TCM component, from a broad macroscopic standpoint that may be viewed as complementary to the narrower microscopic inquiry pursued by Ho. This standpoint is grounded in the theoretical political economy literature (Wong 1999).

Unlike its economistic or market-oriented counterpart - which focuses on the determinants of market success and failure in health care, and the purely economic rationale for state intervention - the political economy approach aims at enhancing the understanding of the interplay between the polity, economy, and society in the process of policy making. The principal preoccupation of researchers who embrace this approach is with the two-way influences emanating from the political and economic spheres and their implications for the distribution of social goods. In this context, health services, an element of that category, are conceptualized in unambiguously political terms in that they involve the quest for access and control over basic material and non-material resources that sustain individual well-being (Wong 1999).

Within this framework, the state is not seen as a detached observer, or referee in its more activist role, but as an institution that enjoys considerable autonomy and power and employs its discretion and resources purposefully in order to maximize internal net benefits and reshape the external environment in an advantageous fashion. In most circumstances, its operations may reflect a basic desire to mediate between different social classes and ameliorate social conditions, yet not necessarily in a balanced manner and ultimately with a view to solidifying the foundations of the capitalist system. Although not blindly wedded to the goal of capital accumulation, the state needs to accord close attention to the impact of its strategies on overall production and reproduction, the "economic" component of political economy (Wong 1999).

Indeed, it is entirely logical for the state to adopt measures conducive to economic prosperity and stability. After all, its own income stream varies with the performance of the economy and it consequently has a vested interest in facilitating economic 
expansion. The corollary presumably is that, while the state endeavors to improve social conditions, it must at the same time strive to sow the seeds of entrepreneurial dynamism and, in the final analysis, profitable capital accumulation. In this respect, the state is confronted with the dual challenge of satisfying political demands for adequate health care and maintaining overall service costs at as low a level as realistically possible. This apparently often accounts for the heavy emphasis placed by state officials on cost containment (Wong 1999).

The power of the state is not confined to resource mobilization and deployment. It extends, directly and indirectly, into the realm of the reproduction of social institutions. In the health care field, this manifests itself, inter alia, in state capacity to define and redefine the role of the family in society and manipulate family relationships. State activities impinge on family functioning along a wide spectrum, but perhaps most notably through its strategies vis-à-vis informal health care (including alternative medicine). By placing the burden of health care on the family and the community, the state may doubtless encounter fewer headwinds in pursuit of its cost containment objectives. In addition, it may have, whether deliberately or inadvertently, a tangible effect on the structure of the family (Wong 1999).

Besides the state, political economists single out the medical profession as a crucial player in the health care system and in health care policy development. There is ample evidence, cross cultural in nature, to support this view. It lends substance to the assertion that the medical profession has exercised dominance over other health care providers, perhaps overwhelmingly so in the case of TCM practitioners in Hong Kong, and patients. Some political economists go as far as to suggest that doctors operate like professional monopolists - consistently seeking ways to erect barriers to protect their autonomy, status, and rewards. The power of the medical profession is often so great that it may be able to materially circumscribe the scope for strategic state action (Wong 1999).

Political economists prefer to examine TCM in the broader context of informal health care (IHC) rather than as a self-contained system of personal services. For this purpose, they equate IHC with the informal diagnosis and treatment of acute illness, activities involving nursing of the sick or management of the symptoms of chronic 
illness/disability, but also encompassing daily "routines" and measures employed to promote health maintenance and prevent diseases, through both care-for-others and self-care. Unlike TCM, informal health care usually relies on unpaid labor, is undertaken in home-based settings, and is underpinned by bonds of kinship. The family has been the mainstay of IHC and its role as a source of long-term health care and social support to its dependent members has overshadowed that of the formal health and social care systems (Wong 1999).

In Hong Kong, the family has played a prominent part in furnishing health care, particularly to the elderly via their immediate female kin. The government has acknowledged and encouraged this contribution, as well as that provided by other informal social entities. Several official documents thus contain favorable and constructive references to the "community as carers," "community as partners in health," "community carers system," and "informal caring network." The substance and spirit of these documents suggest that policy makers have long viewed IHC and TCM as complementary service modalities (placing special emphasis on similarities on the consumption side, given that the consumption of Chinese medicine is predominantly home-based and heavily reliant on domestic labor) and have generally been well-disposed toward their development (Working Party on Primary Health Care 1990; Hospital Authority 1994; Hong Kong Government 1995; Hospital Authority 1995; Hospital Authority 1998).

Taking note of this pattern and favoring a macroscopic political economy perspective over a microscopic policy process one, Wong charted a different path from that of Ho. Rather than portraying the government as largely passive, perhaps even disinterested, party that is driven by a chain of events mostly outside of its control, he painted a picture of an institution pursuing in a deliberate, albeit not invariably coherent, fashion a reasonably well defined strategic agenda. Its vision, which has distinct forward-looking elements, is grounded in the recognition that IHC, including the Chinese medicine variant, is an essential component of health care because of the inherent limitations of modern medicine, specially in catering to the needs of dependent or chronic patients who might otherwise require long-term institutional support, and because patient/ family/ community involvement is a precondition for 
understanding the nature of the illness, complying with treatment protocols, and making necessary adjustments in lifestyle (Wong 1999).

The position is expressed unambiguously in the 1990 report of the Working Party on Primary Health Care (WPPHC). Its authors stated emphatically that certain forms of health care, particularly rehabilitative services, should be delivered in the home environment rather than in formal institutional settings. They further stressed the relevance of a strategy predicated on this logic in a social setting such as that in Hong Kong, where the (Chinese) family constitutes the backbone of the communal structure. The acceptance/ promotion of TCM, within an appropriate framework, is consistent with that stance for it fosters self-reliance and relies on the family as the principal source of funding (without recourse to state subsidies) and physical/ social support (Working Party on Primary Health Care 1990).

From a political economy standpoint, the funding aspect merits close attention, and this is the one Wong chose to highlight. According to him, the policy of nonintervention/ limited intervention, vis-à-vis traditional health care, and by implication its non-regulation/ loose regulation, is rooted to a considerable degree in economic calculus. Demographic changes, rising public expectations, and advances in medical science and technology are constantly driving up the costs of services. Cost containment is thus a top priority, perhaps even more so than in other jurisdictions because of the "rules" governing the relationship between the state and private enterprise and inelastic budgetary procedures. The attraction of IHC and TCM in this context lies in their dependence on unpaid domestic labor (notably female "workers") and commercially-supplied marginal labor that does not impose a heavy financial burden on the public purse (Wong 1999).

That may explain the reluctance to contemplate full integration of traditional health care into the modern state-operated system, as well as the evolution of regulatory policy. A political economy reading of the situational dynamics may be incomplete without incorporating the medical profession into the equation, however. Wong's interpretation of events suggests that it resisted in a determined fashion moves in this direction and that the hybrid configuration that has emerged is partly due to effective muscle flexing by its representatives (with tacit government blessing, in light of the 
financial implications of full integration). The corollary is that a well-established and tightly-organized professional group was able to use its substantial resources and innate leverage (to all intents and purposes, monopoly power) to meaningfully influence strategic decisions impinging on its members' welfare (Wong 1999).

\section{Explanatory Insights Consolidated, Regulatory Lessons}

While extrapolation from the past poses increasing challenges in post-1997 Hong Kong, the SAR government has seldom deviated markedly from time-honored behavioral patterns. It has generally continued to display fiscal restraint and it has on the whole remained unenthusiastic about extending its regulatory tentacles. The ingrained resistance to introducing competition law, which has just recently begun to evaporate after persisting for years in the face of powerful pressures from various quarters, is a telling case in point. For this reason, the events leading to the enactment of the Chinese Medicine Ordinance and beyond may shed valuable light on the forces shaping regulatory outcomes in the territory. The generalizations drawn would have to be sector-specific, or confined to socio-economic regulation of activities in policy domains where modern-type impulses encroach on traditional lifestyles. The work surveyed in the previous section serves as a useful launching pad in that respect, but it is incomplete for the purpose of this exercise.

As the tangled history of the Chinese Medicine Ordinance vividly illustrates, regulation does not evolve in a vacuum. Rather, it is subject to manifold pressures, internal and external (in relation to the decision-making apparatus), reinforcing and restraining. The pressures may combine in one shape or another to create a host of strategic permutations. The analytical framework devised by Kingdom and outlined earlier duly captures the fluidity of the regulatory environment and the near-arbitrary nature of the policies that emanate from it. On the other hand, this highly adaptable structure arguably exaggerates the fluidity and arbitrariness of the system and one may consequently lose sight of the more durable, possibly even semi-constant, dimensions of the picture. The classical political economy approach restores a sense of balance, but it may be overly selective in its focus. These two building blocks need to be augmented and reconfigured. This objective can be realized by examining/ reexamining as broadly as possible the factors driving the demand for regulation, their 
counterparts on the supply (effectively government) side, and the interaction between them.

The demand for regulatory intervention normally originates outside the executive arm of the state machinery (which supplies it in various forms). A useful starting point here is the grassroots community because it is convenient to proceed in a bottom-up fashion in exploring the subject and because TCM, at least prior to its partial institutionalization, could be portrayed as a grassroots phenomenon. Given the wide acceptance of traditional medicine in Hong Kong as well as its entrenched status, substantial presence, and high visibility, it would be reasonable to expect manifestations of grassroots sentiment and interest to surface on a meaningful scale during the period featuring movement away from the colonial era status quo, inevitably culminating in the emergence of a more restrictive but potentially less liberal regime. However, a careful reading of the primary and secondary sources available suggests that such manifestations were conspicuous in their absence.

Political marginalization of the grassroots community was the norm in early colonial era Hong Kong. The emerging local society was divided initially along racial lines, with the civil service (or its upper layers) and British merchants constituting the dominant stratum and Chinese merchants and Chinese laborers the subordinate one. Rapid economic development and effective use of material resources to build groupspecific institutional capabilities paved the way for the transformation of the loose Chinese merchant network into a viable social force. The barriers separating them from their British counterparts receded before long as the homogeneity of class interests assumed greater importance than racial heterogeneity. They were consequently absorbed into the ruling elite and incorporated into the fledgling political system. By contrast, Chinese laborers remained on the fringes of the social pyramid (Chan 1991; Leung 1996; Leung 2003).

This pattern remained largely intact until the outbreak of the Korean War and the imposition of a United Nations embargo on trade with China due to the latter's support for North Korea. The embargo undermined Hong Kong's status as an entrepot and compelled it to re-invent itself as an export-oriented manufacturing center for consumer goods. This externally-induced structural shift coincided with the influx of refugees from Communist China who proved to be a crucial source of 
capital, entrepreneurship, and technical know-how. Genuine business people were a minority among the new arrivals, but they brought with them a large number of skilled employees capable of forming the core of an active industrial proletariat. However, they turned out to be passive, both individually and collectively, and their presence had no tangible impact on prevailing modes of grassroots political participation (Chan 1991; Leung 1996; Leung 2003).

The negligible social influence of the refugee workers partly stemmed from their administratively and psychologically precarious position in an alien and unfamiliar institutional setting (leading to a "don't rock the boat mentality"). The country of origin also played a role in shaping their attitudes, which carried the hallmarks of a familistic and parochial orientation, not conducive to the formation of class consciousness and identity. The decline of old industries, such as docking and shipbuilding, the classical wellsprings of class solidarity, and the proliferation of new ones, characterized by small scale and high labor mobility, reinforced the seemingly paradoxical trend toward increasing grassroots fragmentation and thus political inefficacy (Chan 1991; Lau 1992; Leung 1996; Leung 2003).

In 1978, Communist China reached a historic turning point by embarking on a long journey toward a market-based economy. At that juncture, Hong Kong had matured into an advanced industrial society and, capitalizing on developments across the border in a typically opportunistic fashion, set about transforming itself into an international service center/ global metropolis. By then, the lopsided social structure, consisting of two distant tiers (the ruling elite and working class masses), gave way to a more heterogenous one. Most notably, a new group had emerged, encompassing administrators, managers, representatives of the learned professions, and other whitecollar workers. Its members had solid local roots, having predominantly been born and raised in Hong Kong, and they did not fully share the refugee experience and mentality of the older generations. Yet, they too were slow to make their political mark (Chan 1991; Lau 1992; Leung 1996; Leung 2003).

The non-engagement of the rising middle class could be attributed to the territory's "minimally integrated socio-political system," resting on two unconnected pillars: "an autonomous bureaucratic polity" and an "atomistic Chinese society." The first pillar 
was composed of the civil service, or its top expatriate echelon, and its socioeconomically privileged local "partners," owing to the former their political status. This was an exclusive, inward-looking, and tightly-controlled institution, not prone to welcoming new arrivals and their ideas. The Chinese community, in turn, reflecting its mainland origins (a legacy of malevolent government) and local tradition of selfreliance, also displayed virtually no interest in matters other than those concerning the family (exhibiting "utilitarianistic familism"/ "utilitarian familism"; Lau 1982; Lau and Kuan 1988).

The fit between the minimally integrated socio-political system model and Hong Kong institutional realities has diminished in the past two decades or so (including the period leading to the enactment of the Chinese Medicine Ordinance). The channels of political participation have been redesigned gradually to allow for greater input from without the bureaucratic polity (although there has been a counter trend toward the rebureaucratization of politics) and spontaneous political activity has increased markedly. Formal political institutions, particularly modern-style parties, have gathered strength, assuming a degree of independence from the bureaucratic command-and-control center. Civil society has gained a measure of vitality and has been acting as a source of autonomous political impulses (Leung 1996; Leung 2003; Ma 2007).

Nevertheless, the chasm between the socio-bureaucratic elite and the political periphery persists. Moreover, the political party agenda remains narrow, revolving largely around middle class issues such as democratization, rule of law, quality of life, and the environment. Social welfare questions are addressed, because of a partial ideological and tactical convergence of middle class and working class interests, but otherwise the agenda does not bear a distinct grassroots imprint. By the same token, the family to all appearances continues to serve as the backbone of Hong Kong society. The concept of utilitarianistic familism/ utilitarian familism may have been supplanted by that of a modified "centripetal family," yet the differences between the two lie in the realm of semantics rather than substance (Farber 1975; Salaff 1995; Leung 1996; Leung 2003; Ma 2007). 
The centripetal family relies primarily on its own resources in endeavoring to maximize its well-being, generally shunning support from external sources. At the grassroots level, the historically deep attachment to TCM has not palpably loosened and, due to the comparatively high affordability and limited awareness of potentially adverse side effects, the typical working class household considers this nonmainstream form of health care to be a low-cost and low-risk proposition. The institutionalization of TCM may result in better service quality but also price escalation. From a bottom-up perspective, the trade-off between these two conflicting objectives need not necessarily be resolved in favor of the former. The middle class is progressively gravitating toward modern medicine and the political channels through which it expresses its voice are largely oblivious to TCM and policy responses thereto (Wong 1999; Gauld and Gould 2002; Leung and Bacon-Shone 2006).

The corollary is that, rather paradoxically, an essentially grassroots issue is not receiving effective grassroots attention and is not generating impulses which are productively transmitted into the political arena. On the face of it, it would be reasonable to expect TCM to be subject to influences roughly operating in accordance with the pluralist model of the policy process (the term roughly is employed in this context because Hong Kong's democratization is incomplete and because the model, being predicated on the notion that power rests with citizen groups, arguably presents a somewhat idealized picture of American democracy). However, the behavioral patterns observed seem to correspond more closely to either the elitist model or its subgovernmental counterpart (the former posits that power is concentrated in the hands of a small core of the policy establishment and the latter that it is wielded by a larger group consisting of members of the administrative/ bureaucratic elite, their professional staff, interest group leaders, and selectively coopted experts; Truman 1951; Dahl 1961; Carter 1965; Freeman 1965; Dye and Ziegler 1981).

The other sources of demand for TCM regulation beyond the confines of the bureaucracy include two interest groups, traditional health providers and the medical profession, independent (in the sense of being unaffiliated with the key stakeholders) experts, and the media. An interest group is an organized social aggregate, separate from government albeit often enjoying a close relationship with it, which seeks political goods that it is incapable of supplying itself (Ziegler and Peak 1972; Wilson 
1990). There can be little doubt that TCM practitioners barely meet these requirements. They certainly do not qualify as a concrete group whose contribution to societal tasks is clearly manifest to the target (i.e. the bureaucracy). Given their fragmentation and lack of focus, it would be more appropriate to portray them as a peripheral group which is defined merely by achieved membership/professional identity and which is deemed to have limited functional significance by the target (Wootton 1970).

The linkages between this source and the government are distinctly loose. To the extent that they display any signs of collective activism, traditional health care providers are an outsider group which operates on the fringes of the political system and employs informal tactics (Wilson 1990). Their interest lies in minimum regulation (but not necessarily none in light of the need to control risks and impose barriers to entry) and maximum integration. They have been fortunate to have their "cause" taken up at critical junctures by strategically positioned insiders and outsiders. The trade is undergoing institutionalization, so the picture may change in the not too distant future, yet as matters stand, TCM practitioner demands are expressed by a handful of committed and/or sympathetic policy entrepreneurs (Wong 1999; Gauld and Gould 2002; Leung and Bacon-Shone 2006).

By contrast, the medical profession definitely possesses the attributes of a concrete group whose contribution to societal tasks is clearly manifest to the target group. Indeed, it qualifies as a confident occupational group, commanding substantial resources, intangible as well as tangible, and exhibiting a high degree of selfawareness and a strong sense of purpose (Ziegler and Peak 1972). However, the classical political economy argument that it invariably functions as a utilitymaximizing monopolist bent on hijacking the policy agenda may not be entirely valid. The medical profession has been coopted into the government to the extent that it comfortably plays a pivotal role in shaping health care strategies. Unlike in some other jurisdictions, it thus does not have to engage in complex political maneuvers in order to achieve a favorable wealth redistribution via regulatory capture. While this may be an element in the equation, its demands, effective in that case because of its prominent status, for maximum regulation and minimum integration of TCM may also reflect a professional ideology which remains considerably biased toward modern 
medicine and tinged with skepticism regarding the soundness of the alternatives (Wong 1999; Gauld and Gould 2002; Leung and Bacon-Shone 2006; Wong et al. 2006).

The capabilities and effectiveness of the group notwithstanding, it would be inappropriate to convey the impression that the medical profession has conducted a large-scale and carefully-orchestrated campaign to achieve regulatory outcomes consistent with its goals. Rather, it has mobilized its resources selectively and employed them sparingly, perhaps due to the fact that the perceived final configuration has never been in doubt and the relatively low priority accorded by its members to TCM. Again, a small number of policy entrepreneurs have been at the forefront of efforts to control risks associated with TCM and keep it within proper bounds. The independent experts who have contributed to policy formulation and implementation have also for the most part acted individually, have displayed little cohesion as an agent of change, and have not been able to distance themselves meaningfully from the bureaucracy (whose power of appointment to key committees/ bodies allows it to operate as a gatekeeper; Wong 1999; Gauld and Gould 2002; Leung and Bacon-Shone 2006).

Hong Kong's generally alert, persistent, and assertive media do not focus on TCM in depth, consistently, and within a normative framework. They zero in on the dramatic, eye-catching, and newsworthy aspects; their interest in the subject intensifies and diminishes over the issue-attention cycle; and reporting on traditional healthcare is not a practically-oriented activity for them. There are minor exceptions to the norm, almost exclusively of recent vintage, but this is the overall pattern. The media are thus an implicit source of demand for TCM regulation rather than an explicit one and they possibly impart a measure of instability to the process of institutional reform. At the same time, their impact can be surprisingly strong at turning points because media-induced shifts in the political climate, even if temporary in nature, tend to evoke a bureaucratic response in a territory whose proverbial democratic glass remains half empty. The upshot is that, in the weak sense of the term, the media perform the role of policy advocates for better regulation of risk and greater professional integration (Downs 1972; Leung 1996; Lo 1997; Wong 1999; Lo 2001; 
Gauld and Gould 2002; Leung 2003; Leung and Bacon-Shone 2006; Ma 2007; Wan et al. 2007).

The media's influence reflects the structure of the industry, its impressive size and highly competitive nature. They also serve as an important outlet for political voice of a not fully enfranchised population in a middle class setting characterized by insatiable demand for information. Moreover, the target may be susceptible to media pressure due to the legacy of British rule marked by respect for the industry, or its tolerance, awareness of media power, and a desire to minimize adverse publicity. The colonial government's grip on society had weakened due to a series of events/minicrises which had undermined its legitimacy. Its post-1997 counterpart may have fared even worse as a result of its uninspiring performance (albeit in a challenging environment) and the perception that, promises of autonomy notwithstanding, it functions as an agent of an external principal (i.e., Chinese Communist Party) rather than a domestic (i.e., local population) one. These developments have heightened the sensitivity to media criticism (Scott 1989; Leung 1996; Lo 1997; Lo 2001; Leung 2003; Burns 2004; Scott 2005; Mushkat and Mushkat 2006b; Ma 2007; Wan et al. 2007).

On the supply side, government actions do not fit neatly into any particular theoretical mold. A long period featuring no regulation at all was followed by slow movement toward low-level control by proxy (i.e., self or delegated regulation; see Table 2) and partial integration. Bureaucratic self-interests/ self-regarding preferences/privateregardiness, as distinct from other-interests/ other-regarding preferences/ publicregardiness, may have been at play here as evidenced by the desire to contain costs. However, the government also seems to be driven by a vision of a social order underpinned by the centripetal family. The ideological commitment to such a blueprint and strategies geared to its implementation (including an entrepreneurial health care system) cannot be viewed as strictly parochial in nature, although this is a valid consideration if one chooses to equate self-interest with the preservation of a dynamic market-based economy which generates substantial benefits for the bureaucratic elite (Mitnick 1980).

(Insert Table 2 about here) 
Even if self-interest is a key motivating factor, it should be noted that government regulatory behavior appears to be more consistent with the postulates of maintenance theory than its expansion counterpart (the former assumes that bureaucratic goals are served through defensive maintenance or status quo survival of the institution, whereas the latter hypothesizes that aggressive expansion of the organization and its mandate is the preferred course of action). In this respect, the patterns observed in Hong Kong may differ somewhat from those seen in other jurisdictions. By the same token, a perusal of the relevant official documents suggests that the government is not oblivious to third-party interests. There is thus evidence of concern for the consumer and, at the same time, the producer (as per the consumer protection and producer protection theories; Mitnick 1980).

The concern for the medical profession is clearly stronger than that for the TCM trade, but the interests of the latter, a politically marginal player as well as a technically peripheral producer, are by no means overlooked. Had this not been the case, the transition from the old to the new regulatory regime would probably have been less gentle. The configuration that emerges seems to accord with the balancing concept of the public interest rather than the national or social goals one (the distinction stems from the fact that the public interest may be fulfilled through the simultaneous satisfaction of selected aspects of several particularistic interests or, alternatively, certain national or social objectives may be regarded as being in the public interest and allowed to supersede private ones). The balancing act is of course not necessarily an invariably equitable exercise. In the past, the interests of the bureaucracy and medical profession my have prevailed, but in the future those of the consumer and TCM practitioners may be given slightly greater weight (Mitnick 1980).

A Kingdom/policy window-inspired examination of the events leading to the enactment of the Chinese Medicine Ordinance may suggest that the supply side functions in an unplanned and unsystematic fashion attributed to public entities by the proponents of the garbage-can model of the decision-making process. The garbagecan analogy serves in this context as a conceptual vehicle to strip the aura of scientific authority accorded to decision making in formal institutional settings, particularly in the non-profit sector, by theorists focused on the rational dimension of organizational 
action. Those who highlight its relevance, argue that policy makers seldom have well-defined goals, do not as rule systematically explore the means available to achieve set objectives, and often lack a proper understanding of the cause-effect relationships between means and goals. To express it differently, they improvise without much forethought (or, for that matter, afterthought) as they go along, rendering policy making a distinctly amorphous, contingent, and unpredictable affair (March and Olsen 1979).

The garbage-can model may be the appropriate analytical device for dissecting decision making in certain policy domains in Hong Kong, but health care, including the relatively obscure IHC and TCM components, may not be one of them. This is a sphere of public sector activity where decision makers with solid professional credentials have endeavored, albeit perhaps not always consistently and successfully, to inject an element of rationality into strategic deliberations and where there has been considerable openness to socio-technological innovation. Regarding traditional health care, throughout most of the colonial era the government had adopted a hands-off approach because of the high value placed on family-centered self-reliance in an ultra capitalist environment and in order to minimize the costs of service provision. Awareness of risk had been limited during that period or, to put it more precisely, risk tolerance started to materially diminish only when the territory had transformed itself into a middle class/ post-industrial society. Foreign-controlled modernizing state organs had understandably also been reluctant to tamper with deeply-entrenched traditional practices (Leung 1996; Wong 1999; Gauld and Gould 2002; Leung 2003; Leung and Bacon-Shone 2006).

When a shift in direction materialized, the pace of reform was slow, the adjustment to the new realities was cumbersome, and progress toward an effective fusion of historical legacies and present-day exigencies was uneven. Again, however, this should not be equated with the absence of any method and structure. The government has a strategy for the regulation and integration of TCM. It is not in the form of an elaborate blueprint and there is no specific timetable attached to it. Given the complexities and uncertainties involved, a flexible and open-ended approach may well be sensible in the circumstances. The desire to err on the side of caution (i.e., not to embrace any overly ambitious regulatory and integrative schemes) may also justify 
recourse to such a problem-solving style. While the distinction between rational comprehensive strategies and those which are the product of disjointed incrementalism may not be entirely illuminating (e.g., at times it may be rational not to expand excessively one's horizons and proceed in small steps), it may be convenient to acknowledge that the supply side of the TCM regulatory equation displays a bias toward operating in a disjointed and incremental manner, subject to the qualification that this may be the result of a deliberate design rather than an aimless drift (Dahl 1953; Lindblom 1955; Lindblom 1958; Lindblom 1959; Braybrooke and Lindblom 1963).

Like on the demand side, merely a handful of government officials shape regulatory/ development policy. This partly reflects the fact that TCM does not loom large on the health care agenda. The small number of players on both sides form a largely stable network which mostly functions as a discourse community (the membership in such a group is defined by reference to a specific knowledge base; an interest network, on the other hand, is based on some common material interest). Despite the underlying centrifugal forces at work, this is a surprisingly hegemonic community (see Table 3). Although outsiders occasionally gain entry, members are generally coopted. By the same token, disagreements surface from time to time, but there are no intense pressures to extend regulation/ integration beyond the minimum level achieved thus far. The system is in a state of punctured equilibrium, whereby relatively long periods of no decisive forward movement are interspersed with infrequent bouts of policy realignment (Howlett and Ramesh 2003).

(Insert Table 3 about here)

As the impetus for a regime shift from no regulation/ marginalization to modest control/partial integration originated from the demand side, it may be reasonable to infer that the bureaucracy prefers to take the back seat at key turning points. Organizational inertia may well be a contributing factor here, but not just in the narrow sense of the term, because procedural (as distinct from substantive) rationality may also account for this pattern (stemming from the need to take several steps establish working parties, publish reports, seek feedback, etc. - before embracing a change in strategic direction). Moreover, assuming the role of a change agent may 
prove costly for a conservative government which may be more comfortable being seen as a follower than as a leader when marching into new territory. Last but not least, given the values it espouses (primacy of the family, self-reliance, minimum regulation, no full recognition), it may be convenient for the state to allow societal actors to take the initiative for major reforms (via inside initiation in this case; see Table 4) than rush headlong to dismantle the existing policy architecture (Howlett and Ramesh 2003).

(Insert Table 4 about here)

\section{Conclusion}

Hong Kong has evolved from a modest South China entrepot into a vibrant global metropolis. It serves as a sophisticated provider of complex intermediary services in the Asia-Pacific region and beyond. However, pockets of traditional activity persist and have proved resilient in the face of a steady encroachment by the forces of modernization. TCM is an obvious example for it continues to thrive in this affluent and outward-looking city. Indeed, from a quantitative perspective, it has not fallen behind the highly-institutionalized and generously-supported mainstream health care sector. Throughout most of its existence, TCM had operated out of the public limelight, without any external constraints but also without any recognition. The enactment of the Chinese Medicine Ordinance has propelled it into the policy arena, ushering in a new era characterized by loose regulation and selective absorption into the robust modern health care façade.

Nevertheless, if this experience is typical, one may infer that strong consumer demand for traditional-style services at grassroots level should not be equated with effective demand for regulation of risk and professionalization of the trade. Nor should it be equated with consumer power. Traditional producers also lack the resources to pursue their goals in a meaningful fashion. Representatives of the modern professions and senior civil servants dominate the small circle of policy entrepreneurs that determines regulatory/ developmental outcomes. Their interests and values are skewed in favor of restraint, both in terms of control of risk and integration of traditional modes of service delivery into the organizational mainstream. The 
government role is not straightforward, because it is engaged in a delicate balancing act, but this too reinforces the propensity toward slow motion and incremental adjustment.

The regulation of TCM, and traditional forms of professional activity across the industrialized and industrializing world in general, has attracted scant attention from academic researchers. This oversight is unfortunate because TCM operates on a significant scale throughout Chinese communities, in Northeast/Southeast Asia (e.g., China, Singapore, Malaysia, and Taiwan) and elsewhere (e.g., Australia, Canada, New Zealand, the United Kingdom, and the United States). The corollary is that, as matters stand, our observations, which inevitably reflect Hong Kong's peculiar brand of capitalism and socio-political legacy, cannot be readily integrated with those of other scholars working in the field within an illuminating comparative framework. However, we hope that this detailed case study will furnish a catalyst for systematic inquiries into the subject. The modern state needs to confront the provision of health care via traditional channels explicitly and constructively. Gaining insights into the interplay between the forces of demand and supply driving the regulation of TCM is a vital element of the policy equation.

Table 1 Dimensions of Policy Analysis
Component
Questions to be Addressed
Mode of Inquiry
Process
What triggered the policy
Description, explanation, and how it evolved? evaluation
Content
What are the policies?
Description
Outcome
What are the impacts of policies?
Explanation, evaluation 
Table 2

Typology of Regulation

Regulatee

$\begin{array}{ll}\text { Public } & \text { Private } \\ \text { Regulatee } & \text { Regulatee }\end{array}$

$\begin{array}{lll}\text { Public } & \text { Government } & \text { Traditional } \\ \text { Regulator } & \text { self-regulation } & \text { regulation }\end{array}$

Regulator

Private

Capture

Private

Regulator

self-regulation

Adapted from: Mitnick (1980)

Table 3

Typology of Discourse Communities

Number of Idea Sets

Few Many

$\begin{array}{lll}\text { Yes } & \begin{array}{l}\text { Hegemonic } \\ \text { community }\end{array} & \text { Fractious } \\ & \text { community }\end{array}$

Dominant Idea Set

$\begin{array}{lll}\text { No } & \begin{array}{l}\text { Contested } \\ \text { community }\end{array} & \text { Chaotic } \\ & \text { community }\end{array}$

Adapted from: Howlett and Ramesh (2003) 


\section{Table 4}

\section{Typology of Policy Initiation Mechanisms}

\section{Nature of Public Involvement}

High Low

Societal Actors Outside initiation Inside initiation

\section{Initiator of Debate}

State Consolidation Mobilization

Adapted from: Howlett and Ramesh (2003)

\section{References}

Ash, R. et al. (2003) Hong Kong in Transition (London: Routledge Curzon).

Bailey, S.J. (1995) Public Sector Economics (Basingstoke: Macmillan).

Bailey, S.J. (1999) Local Government Economics (Basingstoke: Macmillan).

Bailey, S.J. (2004) Strategic Public Finance (Basingstoke: Palgrave Macmillan).

Bird, R.M. (1971) Wagner's "law" of expanding state activity, Public Finance, 26(1), pp. 1-26.

Braybrooke, D. and Lindblom (1963) A Strategy of Decision (New York: Free Press).

Burns, J.P. (2004) Government Capacity and the Hong Kong Civil Service (Oxford: Oxford University Press).

Carter, D. (1965) Power in Washington (New York: Random House).

Chan, W.K. (1991) The Making of Hong Kong Society (Oxford: Oxford University Press).

Cheng, T.Y. (1982) The Economy of Hong Kong (Hong Kong: Far East Publications).

Cheng, L.K. and Wong, R.Y.C. (1997) Port Facilities and Container Handling Services (Hong Kong: City University of Hong Kong Press).

Cheng, L.K. and Wu, C. (1998) Competition Policy and Regulation of Business (Hong Kong: City University of Hong Kong Press). 
Chinese Medicine Council of Hong Kong (2006) Regulation of Chinese Medicine Practitioners (Hong Kong: CMCHK).

Cobb, R.W. and Elder, C.D. (1983) Participation in American Politics (Baltimore: Johns Hopkins University Press).

Dahl, R.A. (1953) Politics, Economics, and Welfare (New York: Harper and Row).

Dahl, R.A. (1961) Who Governs? (New Haven: Yale University Press).

de Mesquita, B.B. et al. (1985) Forecasting Political Events (New Haven: Yale University Press).

De Mesquita, B.B. et al. (1996) Red Flag over Hong Kong (Chatham: Chatham House).

Downs, A. (1972) Up and down with ecology - the issue-attention cycle, Public Interest, 28 (2), pp. 38-50.

Dye, T.R. and Ziegler, L.H. (1981) The Irony of Democracy (Monterey:

Brooks/Cole).

Farber, B. (1975) Bilateral kinship, Journal of Marriage and the Family, 37(4), pp. 871-889.

Freeman, J.L. (1965) The Political Process (New York: Random House).

Gambert, S.R. (1994) Literature review and opinion, Geriatric Nephrology and Urology, 4 (3), pp. 203-208.

Gauld, R. and Gould, D (2002) The Hong Kong Health Sector (Hong Kong: Chinese University Press).

Government of the Hong Kong Special Administrative Region (November 30, 2000) Press Release.

Hall, C. (1996) Uncertain Future (Hong Kong: Chinese University Press).

Hay, J.W. (1997) Health Care in Hong Kong (Hong Kong: Chinese University Press).

Ho, H.C.Y. and Chau, L.C. (1989) The Hong Kong Economic System (Hong Kong: Asian Research Center).

Ho, L.S. (1997) Health Care Delivery and Financing in Hong Kong (Hong Kong: City University of Hong Kong Press).

Ho, P.L.H. (2002) Agenda-setting for the regulation of traditional Chinese medicine in Hong Kong, Asian Journal of Public Administration, 24 (2), pp. 257-285.

Hong Kong Government (1995) White Paper on Rehabilitation (Hong Kong: 
Government Printer).

Hospital Authority (1994) Business Plan 1994-95 (Hong Kong: Hospital Authority).

Hospital Authority (1995) Annual Plan 1995-96 (Hong Kong: Government Printer).

Hospital Authority (1998) Annual Plan 1998-99 (Hong Kong: Hospital Authority).

Howlett, M. and Ramesh, M. (2003) Studying Public Policy (Oxford: Oxford University Press).

Jao, Y.C. (2001) The Asian Financial Crisis and the Ordeal of Hong Kong (Westport: Quorum Books).

Kingdom, J.W. (1997) Agendas, Alternatives, and Public Policies (Upper Saddle River: Pearson Education).

Kwong, K.S. (1988) Toward Open Skies and Uncongested Airports (Hong Kong: Chinese University Press).

Kwong, J.A. (1990) Market Environmentalism (Hong Kong: Chinese University Press).

Lam, P.L. (1997) Competition in Energy (Hong Kong: City University of Hong Kong Press).

Lam, P.L. and Chan, Y.C. (1997) Privatizing Water and Sewage Services (Hong Kong: City University of Hong Kong Press).

Lam, P.L. and Chan, S. (2000) Competition in Hong Kong's Gas and Capacity Industry (Hong Kong: Chinese University Press).

Lau, S.K. (1982) Society and Politics in Hong Kong (Hong Kong: Chinese University Press).

Lau, S.K. and Kuan, H.C. (1988) The Ethos of the Hong Kong Chinese (Hong Kong: Chinese University Press).

Lau, S.K. (1992) Indicators of Social Development (Hong Kong: Institute of AsiaPacific Studies, Chinese University of Hong Kong).

Lee, R.P.L. (1980) Perceptions and uses of Chinese medicine among the Chinese in Hong Kong, Culture, Medicine, and Psychiatry, 4 (4), pp. 345-375.

Lethbridge, D. and Ng S.H. (2000) The Business Environment of Hong Kong (London: Routledge Curzon).

Leung, B.K.P. (1996) Perspectives on Hong Kong Society (Hong Kong: Oxford University Press). 
Leung, B.K.P. (2003) Hong Kong (Aldershot: Ashgate).

Leung, K.S.Y. and Chan, K (2004) Regulatory system of proprietary Chinese medicine in Hong Kong, Journal of Complementary and Integrative Medicine, 12 (1), pp. $185-189$.

Leung, G.M. and Bacon-Shone, J. (2006) Hong Kong's Health System (Hong Kong: Hong Kong University Press).

Lindblom, C.E. (1955) Bargaining (Los Angeles: Rand Corporation).

Lindblom, C.E. (1958) Policy analysis, American Economic Review, 48 (3), pp. 298312.

Lindblom, C.E. (1959) The science of muddling through, Public Administration Review, 19 (1), pp. 79-88.

Lo, S.H. (1997) Democratization in Hong Kong (London: Macmillan).

Lo, S.H. (2001) Governing Hong Kong (New York: Nova Science).

Ma, N. (2007) Political Development in Hong Kong (Hong Kong: Hong Kong University Press).

March, J.G. and Olsen, J.P. (1979) Ambiguity and Choice in Organizations (Bergen: Universitetsforlaget).

Mitnick, B.M. (1980) The Political Economy of Regulation (New York: Columbia University Press).

Mok, E. (2001) Hong Kong's health system and its challenges, Journal of Nursing Administration, 31 (11), pp. 520-523.

Mueller, M. (1991) International Telecommunications in Hong Kong (Hong Kong: Chinese University Press).

Mushkat, M. (1990) The Economic Future of Hong Kong (Boulder: Rienner).

Mushkat, M. and Mushkat, R. (2006a) The transfer of property rights from the public to the private sector in Hong Kong, Global Economic Review, 35 (4), pp. 445-461.

Mushkat, M. and Mushkat, R. (2006b) Political economy of governance and public trust, International Quarterly for Asian Studies, 37 (1/2), pp. 87-117.

Mushkat, R. (2006) Hong Kong's exercise of external autonomy, International and Comparative Law Quarterly, 55 (4), pp. 963-972.

Peacock, A.T. and Wiseman, J. (1961) The Growth of Public Expenditure in the United Kingdom (Princeton: Princeton University Press. 
Peebles, G. (1988) Hong Kong's Economy (Oxford: Oxford University Press).

Preparatory Committee on Chinese Medicine (1997) Report (Hong Kong:

Government Printer).

Preparatory Committee on Chinese Medicine, Consultation on the Development of Traditional Chinese Medicine (Hong Kong: Government Printer).

Rabushka, A. (1973) The Changing Face of Hong Kong (Washington: American Enterprise Institute).

Rabushka (1976) Value for Money (Stanford: Hoover Institution).

Rabushka, A. (1980) Hong Kong (Hong Kong: Heinemann).

Salaff, J. (1995) Working Daughters of Hong Kong (New York: Columbia University Press).

Scott, I. (1989) Political Change and the Crisis of Legitimacy in Hong Kong (Hong Kong: Oxford University Press).

Scott, I. (2005) Public Administration in Hong Kong (Singapore: Marshall Cavendish).

Truman, D.B. (1951) The Governmental Process (New York: Knopf).

Wan, W.M. et al. (2007) Contemporary Hong Kong Politics (Hong Kong: Hong Kong University Press).

Wilson, G.K. (1990) Interest Groups (Englewood Cliffs: Prentice-Hall).

Wong, T.W., Wong, S.L., and Donnan, P.B. (1993) A study of traditional Chinese medicine practitioners in Hong Kong, Journal of the Hong Kong Medical Association, 45 (4), pp. 285-290.

Wong, R.Y.C. (1998) On Privatizing Public Housing (Hong Kong: City University of Hong Kong Press).

Wong, V.C.W. (1999) The Political Economy of Health Care Development and Reforms in Hong Kong (Aldershot: Ashgate).

Wong, W.C.W. et al. (2006) Strengths, weaknesses, and development of traditional Chinese medicine in the health system of Hong Kong, Journal of Alternative and Complementary Medicine, 12 (2), pp. 185-189.

Working Party in Chinese Medicine (1991) Interim Report (Hong Kong: Government Printer).

Working Party on Chinese Medicine (1994) Final Report (Hong Kong: Government Printer). 
Working Party on Primary Health Care (1990) Health for All (Hong Kong: Government Printer).

Wootton, G. (1970) Interest-Groups (Englewood Cliffs: Prentice-Hall).

Youngston, A.J. (1982) Hong Kong (Hong Kong: Oxford University Press).

Ziegler, L.H. and Peak, G.W. (1972) Interest Groups in American Society (Englewood Cliffs: Prentice-Hall). 